mode of presentation of information and the hypothetical vs real target persons. There is a lingering doubt on the part of some research workers that findings based on "artificial" laboratory procedures may not be generalizable to real-life situations. While this possibility has not been unequivocally discounted, nevertheless, within limits, the reality of the target is not a crucial variable for personality judgments. If such results could be replicated and the actual cognitions of the judges regarding the reality of the target persons assessed, then perhaps one could more readily accept the results of social perception experiments in which no attempts whatsoever are made to convey the reality of the stimulus person.

\section{REFERENCES}

ANDERSON. N, H. Application of an additive model to impression formation. Science, $1962,138,817-818$.

ANDERSON, N. H. Averaging versus adding as a stimulus-combination rule in impression formation. Journal of Experimental Psychology, 1965, 70 394-400.

JACKSON, D. N. The measurement of perceived personality trait relationships. In N. F. Washburne (Ed.), Decisions, values, and groups. Vol. 2. New York: Pergamon Press, 1962.

JACKSON, D. N. Personality Research Form. Goshen, N.Y: Research Psychologists Press, 1967.

LAY, C. H., \& JACKSON, D. N. Analysis of the generality of trait inferential relationships. Journal of Personality \& Social Psychology, 1969, 12, 12-21.

LAY, C. H. Trait-inferential relationships and judgments about the personalities of others. Canadian Journal of Behavioral Science, 1970, 2, 1-17.

TORGERSON, $\mathrm{W}$. S. Theory and methods of scaling. New York: Wiley, 1958.

\title{
The effect of simulated receptor aging on two types of visual illusions
}

\author{
KRISTEN P. SJOSTROM and ROBERT H. POLLACK \\ University of Georgia, Athens, Ga. 30601
}

A Type I (Delboeuf illusion) and Type II (Usnadze effect) illusion were viewed both through and without a yellow filter by younger and older groups of adults. The filter served to simulate receptor aging by decreasing the visual sensitivity of the Ss. The magnitude of the Type I illusion decreased at both age levels when viewed through the filter, but the magnitude of the Type II illusion did not change. The results indicate that different mechanisms produce the ontogenetic trends of the two types of illusions.

Pollack (1969) has proposed recently that the mechanisms underlying the ontogenetic trends of Type I and Type II visual illusions are distinct. The decreasing illusory effect of Type I phenomena accompanying increasing chronological age is believed to be produced by visual receptor aging. The growing magnitude of Type II phenomena, on the other hand, is thought to be related to cognitive functioning.

Pollack's argument (1969) about Type I phenomena is based on the decreasing sensitivity of the visual receptors which occurs with increasing chronological age. This loss of sensitivity has been measured in terms of both the amount of light reaching the retina (Weale, 1961a) and the absolute threshold to light stimulation (Birren, Bick, \& Fox, 1948; Luria, 1960; Robertson \& Yudkin, 1944; Stevens, 1948; Weale, 1961b). Weale (1963) states that the aging process is produced by physiological factors such as the yellowing of the crystalline lens and decreasing diameter size of the pupils. Corresponding to the general loss of sensitivity of the receptors, Pollack (1969) feels that there is a decline in sensitivity to the variables which underlie the configuration of Type I phenomena, causing the illusory effect of the figures to decrease.

In support of the view by Pollack (1969), investigations of Type I illusions have revealed that the magnitude of the illusory effect is enhanced with increases in the brightness difference between the inducing parts of the figures and their backgrounds (Oyama, 1961; Weintraub, Wilson, Green, \& Palmquist, 1969). Furthermore, Pollack (1963) discovered that sensitivity to brightness contrast declines as age increases from 8 to 12 years. The increasing contour detectability thresholds were also found (Pollack, 1963) to be negatively correlated $(\mathrm{r}=.49, \quad \mathrm{p}<.01)$ with magnitude of the Müller-Lyer illusion, a Type 1 phenomenon.

Type II phenomena, however, unlike Type I phenomena, are correlated with intelligence (Spitz \& Blackman, 1958, 1959) and are thought to be related to higher level activities of organizing sense data. Pollack. (1969) states that the presentation of Type II illusions usually involves a sequence of discrete stimulus events designed to maximize contrast when the traces of the events are centrally compared and contrasted. The age trend of Type II phenomena is thus believed to be produced by a developing ability to make successive comparisons.

In the present investigation, visual receptor aging was simulated by requiring $S s$ to view through a yellow filter the Delboeuf illusion (D) and Usnadze effect (U), a Type I and Type II phenomenon, respectively (Piaget, 1969). The purpose of the experiment was to determine if the magnitude of the two types of illusions would be differentially affected by a reduction in the visual sensitivity of the Ss. According to the view presented by Pollack (1969), it was expected that under the simulated condition the magnitude of $D$ would decrease but the magnitude of $U$ would not change.

\section{SUBJECTS}

There were eight males and eight females in each of two age groups. The mean age and standard deviation in years of the younger group were 20.94 and 1.51, while those of the older group were 45.56 and 4.69 , respectively. All Ss had a reported visual acuity of 20/30 or better.

APPARATUS AND PROCEDURE

All stimuli were constructed on $5 \times 7$ in. cards for tachistoscopic use. The test circle for all comparisons was $9.6 \mathrm{~mm}$ in diam. The comparison circles varied in $.5-\mathrm{mm}$ steps from: $\mathbf{5 . 6}$ to $10.6 \mathrm{~mm}$ for $U, 8.6$ to $14.1 \mathrm{~mm}$ for $\mathrm{D}$, and 7.1 to $12.1 \mathrm{~mm}$ for the control task.

The inducing circles of $U$ were 4.1 and $14.1 \mathrm{~mm}$ in diam. The former was concentric to the comparison circle, and the latter was concentric to the test circle. The inducing circle of $D$ was $14.1 \mathrm{~mm}$ in diam and was concentric to the test circle.

For each stimulus, the test circle was centered $12.1 \mathrm{~mm}$ to the left and the comparison circle $12.1 \mathrm{~mm}$ to the right of a fixation dot. The maximal visual angle subtended by the stimuli was 2 deg wide by $3 / 4$ deg high.

All exposure times were $500 \mathrm{msec}$. For the U, a $500-\mathrm{msec}$ interval occurred between presentation of the inducing circles and the test and 
comparison circles. For $D$, the inducing circle was presented simultaneously with the test and comparison circles.

Viewing was monocular with the right eye under all conditions of the experiment. All Ss wore a pair of sunglasses which had both lenses removed. In place of the left lens, a piece of black posterboard always completely occupied the space. Under the nonsimulated condition, the right space was left unoccupied.

Under the simulated condition, the right space of the sunglasses was occupied by a piece of black posterboarc, with a hole $4 \mathrm{~mm}$ in diam cut out of is center. A piece of Kodak Wratten gelatin filter was taped completely over the hole. The Kodak filter (8K2) was specified to have a luminous transmittance of $86.6 \%$ and a dominant wavelength of 581.2 millimicrons.

The stimuli were presented in a three-channel electronic tachistoscope (Model GB) made by Scientific Prototype Manufacturing Corporation. The intensities of all three channels was kept constant at 6.8 apparent foot-candles as measured at the eyepiece by a Macbeth illuminometer. The illumination decreased to 4.0 apparent foot-candles, however, when transmitted through the filter.

Each $S$ viewed both illusions through and without the filter. All Ss came to two experimental sessions, and only one illusion under both conditions was presented each session. The order of presentation of illusions and conditions was varied among Ss so that each combination of illusion and condition occurred an equal number of times in each ordered position.

During each presentation of the stimulus, $\mathbf{S}$ was told to state whether the comparison circle was either larger or smaller than the test circle. Before each measurement of the illusion, a control measure was obtained by finding the $S$ 's point of subjective equality for the test circle in the absence of inducing circles under the same viewing conditions as for the illusion. For all conditions of the experiment, four trials of the stimuli were given employing the convergent method of limits. The initial stimulus of each trial was composed of either the largest or smallest comparison circle in abba order.

The criterion used for determination of the point of subjective equality was a change in response maintained for two consecutive values in the ascending or descending order. All illusion magnitudes were determined by subtracting algebraically the control measure which immediately preceded it.

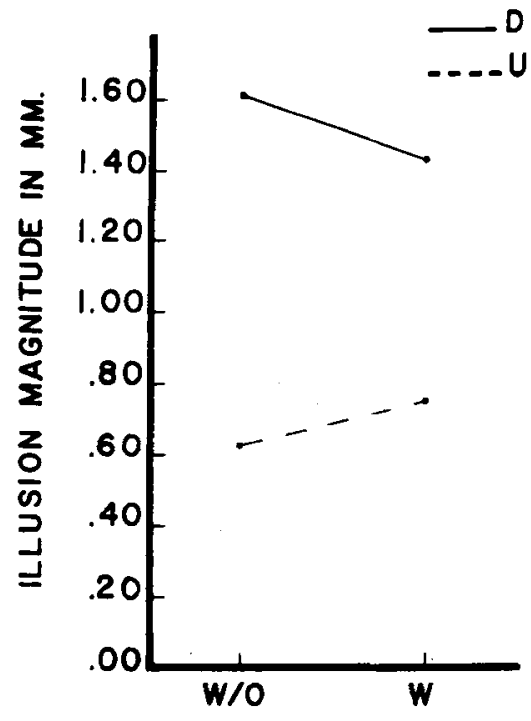

Fig. 1. Interaction between Delboeuf (D) and Usnadze (U) illusions without $(w / o)$ and with (w) filter conditions.

\section{RESULTS}

Significant illusory effects were found for both $D$ and $U$, the test circle being overestimated in $D$ and underestimated in $U$. No sex differences were found in a preliminary analysis of the data.

An Age Group by Illusion by Condition analysis of variance with repeated measures on illusion and condition was calculated. Only two F values reached significance. First, it was found that the illusory effect of $D$ was greater than $U$ ( $F=85.00$, $\mathrm{df}=1,30, p<.01)$. Second, and more interesting, an Illusion by Condition interaction $(\mathrm{F}=4.44, \mathrm{df}=1,30$, p <.05) was revealed (see Fig. 1). A Newman-Keuls test of the interaction showed, as predicted, that when viewed through the filter, the magnitude of the Type I phenomenon decreased $(p<.05)$ but the magnitude of the Type II phenomenon did not change.

\section{DISCUSSION}

The results appear to be in support of Pollack's theory (1969). The data show that a decrease in the sensitivity of the visual receptor system produces a decrease in the illusory effect of $D$ but not $U$. There is, therefore, justification for differentiating the mechanisms producing the characteristic distortions of the two types of illusions. It is the feeling of the present authors that the decrease in sensitivity of the human visual apparatus, which occurs with increasing chronological age, is indeed sufficient to produce a decrease in Type I phenomena but not Type II phenomena.
Since the Age by Condition interaction in the present study did not approach significance, it appears that there is an absolute effect of the filter. The effect of receptor aging on susceptibility to Type I illusions would thus seem to be additive.

In this experiment, a difference between age groups on illusion magnitude for neither type of phenomena occurred. This finding was expected from the results of Wapner, Werner, \& Comalli (1960). Wapner et al found, with $S$ s between 20 and 80 years of age, that the direction of the age trends of both types of illusion mysteriously reversed in middle age. A difference in illusion magnitude for Type I and Type II phenomena was not found between Ss of the same ages as those of the present study. Thus far, there is not an adequately documented explanation in the literature for the reversals.

\section{REFERENCES}

BIRREN, J. E., BICK, M. W.. \& FOX, C. Age changes in the light threshold of the dark adapted eye. Journal of Gerontology, 1948, 5, 216-221.

LURIA, S. M. Absolute visual threshold and age. Journal of the Optical Society of America, $1960,50,86-87$

OYAMA, T. The illusion of concentric circles as a function of hue and brightness. Hokkaido Report of Psychology, 1961,6, No. 3.

PIAGET, J. The mechanisms of perception. New York: Basic Books, 1969

POLLACK, R. H. Contour detectability threshold as a function of chronological age. Perceptual \& Motor Skills, 1963,17, 411-417.

POLLACK, R. H. Some implication of ontogenetic changes in perception. In $E$. Elkind and J. Flavell (Eds.), Essays in cognitive development: Studies in honor of Jean Piaget. New York: Oxford University Press, 1969. Pp. 365-407.

ROBERTSON, G. W. \& YUDKIN, J Effects of age upon dark adaptation. Journal of Physiology, 1944, 103, 1-8.

SPITZ, H. H., \& BI.ACKMAN, L. S. The Müller-Lyer illusion in retardates and normals. Perception \& Motor Skills, 1958, 219-225

SPITZ. H. H., \& BLACKMAN, L. S. Studies in mental retardation: $I$. A comparison of mental retardates and normals on visual figural aftereffects and reversible figures. Journal of Abnormal \& Social Psychology, 1959, 58, 105-110.

STEVENS, D. M. Relationship between dark adaptation and age. Nature (London), 1946, 157, 376-377.

WAPNER, S., WERNER, H., \& COMALLI, P.. JR. Perception of part-whole relationships in middle and old age. Journal of Gerontology, 1960, 15, 412-416.

WEALE, R. A. Retinal illumination and age. Illuminating Engineer Society, London Transactions, 1961a, 26, 95-100.

WEALE, R. A. Notes on the photometric significance of the human crystalline lens. Vision Research, 1961b, 1, 183-191.

WEALE, R. A. The aging eye. New York: Harper \& Row, 1963.

WEINTRAUB, D. J., WILSON, B., GREEN, R. D., \& PALMQUIST, M Delboeuf illusion: Displacement versus diameter, arc deletions, and brightness contrast. Journal of Experimental Psychology, $1969,80,505-511$. 